ORIGINAL ARTICLE

\title{
Validity and factor structure of the bodybuilding dependence scale
}

\section{Smith, B Hale}

See end of article for authors' affiliations .....................

Correspondence to: Dr Smith, Department of Sport and Exercise Sciences, University College Chester, Parkgate Road Chester $\mathrm{CH} 14 \mathrm{BJ}$,

UK; d.smith@chester.ac.uk

Accepted 11 March 2003
Objectives: To investigate the factor structure, validity, and reliability of the bodybuilding dependence scale and to investigate differences in bodybuilding dependence between men and women and competitive and non-competitive bodybuilders.

Methods: Seventy two male competitive bodybuilders, 63 female competitive bodybuilders, 87 male noncompetitive bodybuilders, and 63 non-competitive female bodybuilders completed the bodybuilding dependence scale (BDS), the exercise dependence questionnaire (EDQ), and the muscle dysmorphia inventory (MDI).

Results: Confirmatory factor analysis of the BDS supported a three factor model of bodybuilding dependence, consisting of social dependence, training dependence, and mastery dependence $(Q=3.16$, $\mathrm{CFI}=0.98, \mathrm{SRMR}=0.04)$. Internal reliability of all three subscales was high (Cronbach's $\alpha=0.92$, 0.92 , and 0.93 respectively). Significant $(p<0.001)$ and moderate correlations were found between all BDS and MDI subscales, and between five of the eight EDQ subscales. A multivariate analysis of covariance, with univariate $F$ tests and Tukey HSD tests, revealed that both male and female competitive bodybuilders scored significantly $(p<0.05)$ higher on all three BDS subscales than the male and female non-competitive bodybuilders. However, there were no significant sex differences on any of the BDS subscales $(p>0.05)$.

Conclusion: The three factor BDS appears to be a reliable and valid measure of bodybuilding dependence. Symptoms of bodybuilding dependence are more prevalent in competitive bodybuilders than non-competitive ones, but there are no significant sex differences in bodybuilding dependence.
$\mathrm{E}$ xercise dependence, a process in which a person feels compelled to exercise and suffers physical and psychological symptoms when exercise is withdrawn, ${ }^{1}$ appears to be commonplace among bodybuilders. ${ }^{2-6}$ Both anecdotal case reports ${ }^{25}$ and academic research ${ }^{36}$ refer to this phenomenon, but until recently it had not been empirically examined. This is somewhat surprising, given that exercise psychology researchers have been interested in exercise dependence in aerobic exercise populations, particularly long distance runners, for some time..$^{7-14}$ This line of research had provided very interesting information on possible correlates and motivational antecedents of exercise dependence in these populations, as well as developing and beginning validation of both general ${ }^{13-14}$ and running specific ${ }^{10-12}$ exercise dependence measures. However, many differences exist in the motivations and psychological characteristics of bodybuilders compared with other exercising populations. ${ }^{36}{ }^{15-17}$ Therefore, the results of this exercise dependence research cannot necessarily be generalised to bodybuilders, and the general exercise dependence measures may not be suitable for use with bodybuilders.

Smith et $\mathrm{l}^{18}$ reasoned that a bodybuilding specific exercise dependence measure needed to be developed to enable examination of exercise dependence in bodybuilders. These authors therefore began validation of the bodybuilding dependence scale (BDS), a nine item measure with a Likert scale answer format. The items were designed to determine the degree to which a bodybuilder satisfies the criteria of Veale, ${ }^{19}$ Morgan, ${ }^{20}$ and Morrow (personal communication, 13 July 1995) for diagnosis of exercise dependence. These criteria are based on or related to the criteria of the diagnostic and statistical manual for mental disorder $\left(D_{S M}{ }^{21}\right)$ for substance dependence, including both biomedical elementsfor example, withdrawal symptoms-and psychosocial elements-for example, interference with social life and occupation. Items were also written based on actual comments obtained from experienced bodybuilders by the investigators and anecdotal evidence. ${ }^{2-4}$ An exploratory factor analysis revealed three subscales: social dependence, training dependence, and mastery dependence. Social dependence appears to reflect the need to be in the bodybuilding social environment, training dependence appears to reflect dependence on the actual activity of lifting weights, and mastery dependence appears to reflect the need to exert control over training schedules.

Further research by Hurst et $a^{22}$ supported the concurrent and construct validity of all three BDS subscales, with experienced bodybuilders scoring significantly higher than inexperienced bodybuilders and weightlifters on these subscales and on the social support survey-clinical form. ${ }^{23}$ In addition, significant correlations were found between all three BDS subscales and the social physique anxiety scale ${ }^{24}$ and a bodybuilding specific version of the athletic identity measurement scale. ${ }^{25}$

Thus, research to date supports the validity of the BDS. However, as noted by Hurst et $a l^{22}$ the three factor model of bodybuilding dependence has not yet been subjected to confirmatory factor analysis. Also, the concurrent validity of the BDS has not been tested by correlating it with a previously validated, general exercise dependence scale, such as the exercise dependence questionnaire (EDQ). ${ }^{14}$ The present study aimed to address this issue, and it was

\footnotetext{
Abbreviations: BDS, bodybuilding dependence scale; $\mathrm{CFI}$, comparative fit index; $E D Q$, exercise dependence questionnaire; $M D I$, muscle dysmorphia inventory; SRMR, standardised root mean square residual
} 
hypothesised that significant, moderate correlations would occur between the BDS and EDQ subscales. Very high correlations would not be expected because of the nonbodybuilding nature of the EDQ, but some moderate relation should exist as both measures purport to measure exercise dependence.

Another way of testing the concurrent validity of the BDS would be to examine its relation to muscle dysmorphia. This has been suggested ${ }^{17}$ as a subtype of body dysmorphic disorder, an intense preoccupation with an imagined or slight physical defect. ${ }^{21}$ According to Lantz et al, ${ }^{17}$ muscle dysmorphics have a distorted body image, see themselves as thin and puny even though they are actually large and muscular, and have a preoccupation with gaining muscle size and definition. Clearly, muscle dysmorphics share behavioural characteristics with exercise dependent individuals, and, indeed, exercise dependence is considered a critical component of muscle dysmorphia. ${ }^{17}$ Therefore it was hypothesised that the BDS subscales would significantly correlate with a measure of muscle dysmorphia, the muscle dysmorphia inventory (MDI). ${ }^{26}$

In addition, a number of potentially important diagnostic issues have yet to be explored, such as the possibility of psychological differences between competitive and noncompetitive bodybuilders. Although bodybuilding is a competitive sport, most people who describe themselves as bodybuilders do not actually compete. ${ }^{3}$ Instead, most bodybuilders aim to increase their muscular size purely for cosmetic reasons rather than to win trophies. Preparing for a bodybuilding competition is an extremely arduous process, involving not only hard weight training, but very stringent dieting and aerobic training to facilitate fat loss, posing practice, and often the use of various muscle building drugs. ${ }^{235}$ Given the extreme nature of the demands involved in competitive bodybuilding, it seems very likely that only those who are very highly committed to the sport would consider competing. As a very high level of commitment is clearly a prerequisite for becoming dependent on an activity, we hypothesised that competitive bodybuilders would score significantly higher than non-competitive bodybuilders on the three BDS subscales.

Sex differences are another important issue yet to be examined with regard to bodybuilding dependence. Symptoms of exercise dependence have been noted in the female bodybuilding population, ${ }^{5}{ }^{6}$ but the extent of this problem or how it compares with the incidence in the male bodybuilding population is not currently known. Therefore, the final aim of this study was to examine differences between men and women in BDS scores. We hypothesised that women would score as highly as men on all three BDS subscales, based on previous anecdotal observations of quite severe exercise dependent related symptoms in female bodybuilders. $^{56}$

\section{METHODS}

\section{Participants and procedures}

A total of 285 bodybuilders (159 men, 126 women; mean (SD) age 27.17 (6.93) years) participated in the study. For the purposes of the between groups comparisons, participants were subdivided into four groups: competitive men $(\mathrm{n}=72$; mean (SD) age 28.43 (7.03) years), competitive women $(\mathrm{n}=$ 63; mean (SD) age 27.50 (6.72) years), non-competitive men ( $\mathrm{n}=87$; mean (SD) age 28.11 (7.81) years) and noncompetitive women $(\mathrm{n}=63$; mean (SD) age 24.56 (5.19) years). Competitive bodybuilders were defined as those who indicated on their questionnaire that they had participated in or were preparing to participate in bodybuilding competition. Written informed consent was obtained from all participants before participating. Informed consent forms and questionnaires were distributed to and collected from participants at several major bodybuilding competitions and several bodybuilding gymnasia in the United Kingdom. Participants were assured that all answers would be confidential.

\section{Instrumentation}

A questionnaire package comprising several scales and items requesting basic information were used in this study.

\section{Bodybuilding dependence scale ${ }^{18}$}

This is a nine item, Likert scored scale designed to determine the degree to which the respondent satisfies the criteria of Veale, ${ }^{19}$ Morgan $^{20}$ and Morrow (personal communication) for the diagnosis of exercise dependence. Exploratory factor analysis revealed three subscales: social dependence, training dependence, and mastery dependence. Each subscale showed satisfactory internal consistency (Cronbach's $\alpha=0.78,0.76$, and 0.75 respectively ${ }^{18}$ ). One item, "If I miss a weight training workout, I feel as though my muscle mass has shrunk", loaded on both the social dependence and training dependence subscales. The item would appear to us to be more an indication of training dependence than social dependence, and it may be that the loading of this item on two factors was a statistical artefact resulting from a relatively low sample size. We therefore decided, for the statistical analyses, to include this question as part of the training dependence subscale only. Evidence for construct validity of the BDS has been provided by Smith et $a l^{18}$ and Hurst et al ${ }^{22}$ using the known group difference method. The concurrent validity of the BDS has also been supported by Smith et al and Hurst et al, who found significant positive correlations between the three subscales and the athletic identity measurement scale, ${ }^{25}$ the physical self perception profile, ${ }^{27}$ the social physique anxiety scale, ${ }^{24}$ and the social support survey-clinical. ${ }^{23}$

\section{Exercise dependence questionnaire ${ }^{14}$}

The EDQ is a 29 item Likert scale questionnaire designed to assess the extent of exercise dependence. Exploratory factor analysis revealed eight factors: interference with family and friends, positive reward, withdrawal symptoms, exercise for weight control, insight into problem, exercise for social reasons, exercise for health reasons, and stereotyped behaviour. Ogden et al ${ }^{14}$ have shown acceptable internal reliability for each subscale (Cronbach's $\alpha=0.81,0.80,0.80 .0 .78,0.76$, $0.76,0.70$, and 0.52 respectively), and concurrent validity has been shown by significant positive correlations between the EDQ subscales and the eating attitudes test ${ }^{28}$ and the profile of mood states. ${ }^{29}$

\section{Muscle dysmorphia inventory ${ }^{26}$}

The MDI is a 27 item Likert scale questionnaire based on the model of characteristics associated with muscle dysmorphia proposed by Lantz et al. ${ }^{17}$ Confirmatory factor analysis supported a six factor structure (size/symmetry, supplement use, exercise dependence, pharmacological use, dietary behaviour, and physique protection $\left.{ }^{26}\right)$. All subscales have shown acceptable internal reliability (Cronbach's $\alpha=$ $0.72-0.94)$. Significant correlations between the MDI subscales and the training dependence subscale of the BDS ${ }^{18}$ and between the MDI subscales and the drive for thinness subscale of the eating disorder inventory ${ }^{30}$ have provided evidence of convergent validity. ${ }^{26}$

\section{Data analysis}

A confirmatory factor analysis was performed on the BDS using AMOS 4.0 (Smallwater Corporation, Chicago, Illinois, USA, 2001). Several criteria were used to test the hypothesised three factor structure. The traditional measure of fit for 


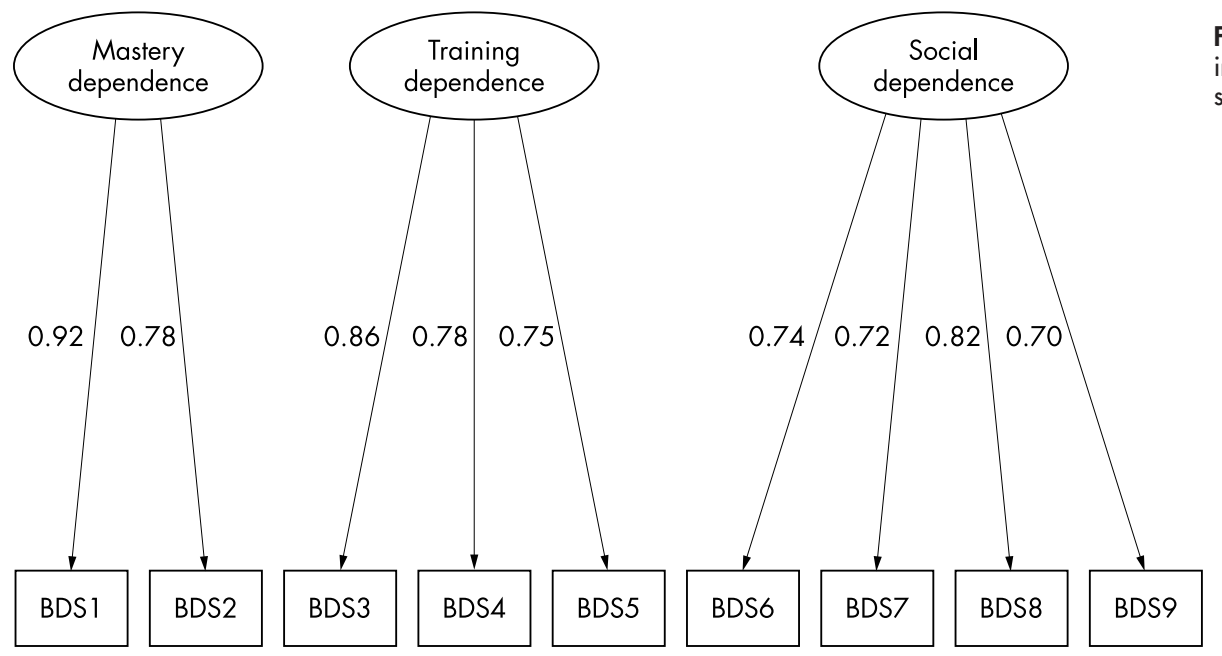

Figure 1 Factor loadings for individual BDS items on their respective subscales. confirmatory factor analysis models is the $\chi^{2}$ goodness of fit test statistic. A $\chi^{2} / \mathrm{df}$ ratio ( $Q$ value) between 2 and 5 indicates a good fit. ${ }^{31}$ However, this is oversensitive with large sample sizes. $^{32}$ Therefore, other indices were also used, namely the comparative fit index (CFI) and the standardised root mean square residual (SRMR). The CFI shows the improvement in fit of the model compared with a completely independent model, and the SRMR shows the difference between the sample covariances and those derived from the model. According to Kline, ${ }^{32}$ to be considered acceptable, a model should have a CFI greater than 0.90 and an SRMR less than 0.10 . In addition, to examine the fit for individual BDS items, factor loadings were examined.

For the between groups analyses, participants were divided into four groups: competitive men, competitive women, noncompetitive men, and non-competitive women. A one way multivariate analysis of covariance was performed to determine whether the BDS scores of these four groups differed. Experience was entered as a covariate because previous research ${ }^{7}$ has indicated that experienced bodybuilders scored significantly higher in bodybuilding dependence than less experienced ones.

Pearson product-moment correlations were calculated to examine the relations between the three BDS subscales and the six subscales of the MDI and eight subscales of the EDQ. Because of the large number of correlations being performed, a Bonferroni adjustment was applied-that is, $\alpha$ level (0.05) divided by the number of correlations (45), giving an adjusted $\alpha$ level of 0.001 .

\section{RESULTS}

The confirmatory factor analysis revealed acceptable fit indices for the three factor model $(Q=3.16$, CFI $=0.98$, SRMR $=0.04)$. Thus, this model appears to provide an adequate explanation of the relations between the items. In addition, all the items had factor loadings of at least 0.80 on the appropriate factor (fig 1). The correlations among the BDS subscales were all moderately high. Social dependence correlated significantly with training dependence $(r=0.55$, $\mathrm{p}<0.001)$ and mastery dependence $(r=0.48, \mathrm{p}<0.001)$, and training dependence correlated significantly with mastery dependence $(r=0.41, \mathrm{p}<0.001)$. This should be expected as they are measuring different aspects of the same underlying construct. The Cronbach's $\alpha$ calculations for each BDS subscale showed high internal reliability $(0.92,0.92$, and 0.93 for social dependence, training dependence, and mastery dependence respectively). The correlations between the BDS subscales and the MDI and EDQ subscales (table 1) showed moderately significant values. However, no significant correlations were found between the BDS subscales and the EDQ subscales of exercise for weight control, exercise for health reasons, and stereotyped behaviour.

The multivariate analysis of covariance revealed a significant overall effect for group (Wilks' $\lambda=0.70, F_{9,676.73}=$ 12.13, $\mathrm{p}<0.001)$. There was also a significant effect for experience, the covariate (Wilks' $\lambda=0.97, F_{3,278}=2.66$, $\mathrm{p}<.05$ ). This only accounted for $2.8 \%$ of the variance, but, as it was significant, the multivariate analysis of covariance was performed in preference to a multivariate analysis of variance. Univariate $F$ tests for group were significant for all the BDS scales, with BDS social dependence $\left(F_{3,280}=\right.$ 17.10, $\mathrm{p}<0.001)$, training dependence $\left(F_{3,280}=29.52\right.$, $\mathrm{p}<0.001)$, and mastery dependence $\left(F_{3,280}=17.45\right.$, $\mathrm{p}<0.001$ ) showing significant between group differences. Tukey HSD tests showed that the BDS social dependence, training dependence, and mastery dependence scores of the competitive men and women were significantly $(p<0.001)$ greater than those of the non-competitive men and women.

Table 1 Pearson product-moment correlations for bodybuilding dependence, exercise dependence, and muscle dysmorphia

\begin{tabular}{|c|c|c|c|c|c|c|c|c|c|c|c|c|c|c|}
\hline \multirow[b]{2}{*}{ BDS } & \multicolumn{6}{|l|}{ MDI } & \multicolumn{8}{|l|}{ EDQ } \\
\hline & Size & Supp & ExDp & Pharm & Diet & $\mathrm{PhPr}$ & Int & PosR & WSy & ExS & ExW & $\ln P$ & ExH & $S+B$ \\
\hline SocDp & $0.45^{*}$ & $0.58^{*}$ & $0.55^{*}$ & $0.64^{*}$ & $0.66^{*}$ & $0.47^{*}$ & $0.51^{*}$ & $0.49^{*}$ & $0.65^{*}$ & $0.60^{*}$ & 0.22 & $0.39 *$ & 0.14 & 0.05 \\
\hline TrnDp & $0.54^{*}$ & $0.53^{*}$ & $0.57^{*}$ & $0.69^{*}$ & $0.66^{*}$ & $0.56^{*}$ & $0.49^{*}$ & $0.52^{*}$ & $0.71^{*}$ & $0.36^{*}$ & 0.25 & 0.37 & 0.12 & -0.02 \\
\hline$M s t D p$ & $0.42^{*}$ & $0.48^{*}$ & $0.51^{*}$ & $0.50^{*}$ & $0.57^{*}$ & $0.52^{*}$ & $0.38^{*}$ & $0.46^{*}$ & $0.68^{*}$ & $0.36^{*}$ & 0.11 & $0.36^{*}$ & 0.05 & -0.09 \\
\hline
\end{tabular}

BDS, Bodybuilding dependence scale; MDI, muscle dysmorphia inventory; EDQ, exercise dependence questionnaire; SocDp, TrnDp, MstDp, social, training, and mastery dependence; Size, size/symmetry; Supp, supplement use, ExDp, exercise dependence, Pharm, pharmacological use, Diet, dietary behaviour; PhPr, physique protection; Int, interference with family and friends; PosR, positive reward, WSy, withdrawal symptoms; ExS, exercise for social reasons; ExW, exercise for weight control; InP, insight into problem; ExH, exercise for health reasons; StB, stereotyped behaviour. ${ }^{*} p<0.001$. 
Table 2 Means (SD) BDS social dependence (SocDp), training dependence ( $\operatorname{TrnDp}$ ), and mastery dependence (MstDp) for male competitive bodybuilders, female competitive bodybuilders, male non-competitive bodybuilders, and female non-competitive bodybuilders

\begin{tabular}{lllll}
\hline Scale & Male competitive & Female competitive & $\begin{array}{l}\text { Male non- } \\
\text { competitive }\end{array}$ & $\begin{array}{l}\text { Female non- } \\
\text { competitive }\end{array}$ \\
\hline BDS-SocDp & $19.25(5.35)$ & $20.79(6.81)$ & $15.01(5.73)$ & $14.19(5.84)$ \\
BDS-TrnDp & $15.44(3.70)$ & $16.41(3.57)$ & $10.95(4.57)$ & $12.11(3.91)$ \\
BDS-MstDp & $10.35(2.35)$ & $10.06(3.00)$ & $7.45(3.10)$ & $7.83(3.30)$ \\
\hline
\end{tabular}

However, there were no significant differences between competitive men and competitive women or between noncompetitive men and non-competitive women ( $p>0.05$ in all cases; see table 2 for means).

\section{DISCUSSION}

The confirmatory factor analysis strongly supports the three factor model of bodybuilding dependence originally suggested by Smith et al. ${ }^{18}$ All fit indices used indicated a strong fit of the model to the BDS. In addition, the internal reliability of the three subscales was also strongly supported. It therefore appears that this phenomenon is indeed multifaceted, involving dependence on the social aspects of bodybuilding training (social dependence), the actual weight training itself (training dependence), and a desire to exert control over training schedules (mastery dependence).

The concurrent validity of the BDS was strongly supported by the significant correlations between the BDS and MDI subscales. As noted earlier, muscle dysmorphia and exercise dependence appear to have clear conceptual links, and exercise dependence can be seen as part of the pattern of behaviour that characterises the muscle dysmorphic person. The fact that all the BDS subscales correlated significantly with the MDI subscales supports the findings of Hurst and colleagues, ${ }^{22}$ who also found support for the concurrent validity of all three subscales.

The concurrent validity of all three BDS subscales was also supported by the significant correlations with five of the EDQ subscales. At first sight, it may appear problematic that no significant correlations were found between the BDS subscales and the remaining three EDQ subscales, but it is important to consider the content of these EDQ subscales. Exercise for weight control relates mainly to the motive to lose weight, including questions such as "After an exercise session I feel thinner". Although many bodybuilders do desire to have a low level of body fat, the main aim of their training is to develop larger muscles, and so this subscale may simply not be relevant enough to this participant population. The degree to which the other two subscales in question, exercise for health reasons and stereotyped behaviour, actually relate to exercise dependence can be questioned. In our view, individuals may well exercise for health reasons without displaying symptoms of exercise dependence, and none of the questions in this subscale relate very clearly to any of the common criteria used for diagnosing exercise dependence. ${ }^{19} 20$ In the case of the stereotyped behaviour subscale, it appears that people may well exercise for the same amount of time and at the same time each week without necessarily being dependent on exercise. Therefore, we contend that this subscale may not effectively discriminate between exercise dependent and non-exercise dependent bodybuilders. It does not seem to be a major concern that no significant correlations were found between BDS subscales and these EDQ subscales.

As hypothesised, the competitive bodybuilders scored significantly higher on all three BDS subscales than the non-competitive bodybuilders. Preparing for bodybuilding competition is an extremely arduous activity, and those who possess an obsessive attitude towards their bodybuilding are far more likely to participate in such competition than bodybuilders whose approach is more casual. This finding further clarifies previous findings of Hurst et al, ${ }^{22}$ who reported that more experienced bodybuilders showed greater exercise dependence than non-experienced bodybuilders. As experience was controlled as a covariate, the differentiating factor determining dependence in bodybuilders may be the obsessive desire to compete in bodybuilding events. Sport and clinical psychologists working with competitive bodybuilders should be careful to ensure that their clients' training programmes are organised so that they maintain a balanced lifestyle with sufficient time devoted to family, friends, hobbies, etc.

The lack of sex differences in BDS scores illustrates the fact that bodybuilding dependence is not only a problem for men. This finding provides quantitative evidence supporting case studies $^{56}$ that have previously suggested that exercise dependence is also a serious problem in the female bodybuilding population. These findings further suggest that the claim made in The Adonis complex by Pope et al, ${ }^{33}$ that muscle dysmorphia and exercise dependence are a predominantly male concern in western society, may be unfounded. Therefore, doctors and sport psychologists should be alert to possible exercise dependence in female bodybuilders who present with relevant symptoms such as overuse injuries, severe withdrawal symptoms when unable to train, training when ill or injured, and training interference with family and friends.

In conclusion, the three factor BDS appears to be a reliable and valid measure of bodybuilding dependence, which would appear to be more prevalent among competitive bodybuilders than non-competitive bodybuilders no matter what sex. However, more research is clearly needed on this important topic. For example, although the internal reliability of the BDS is very high, its test-retest reliability has not yet been examined. Also, although early research ${ }^{18}$ found no relation between anabolic steroid use and bodybuilding dependence, further research is needed, with larger samples and more detailed information on specific drug usage and dosage.

\section{Take home message}

This research provides strong support for the three factor model of bodybuilding dependence. Bodybuilding dependence appears to affect male and female bodybuilders equally, despite previous claims that this is predominantly a male problem, but competitive bodybuilders of both sexes score higher on all three factors than non-competitive bodybuilders. Therefore sport psychologists and coaches working with competitive bodybuilders need to be particularly aware of this potential problem. 
Perhaps most importantly, although the BDS has already proved useful as a research instrument, much more research is required to enable it to be used in a clinical capacity. Cut off scores need to be developed, and the validity of dependent/ non-dependent distinctions-for example, false positives, false negatives-needs to be evaluated. Such research will enable the BDS to be used to identify bodybuilders who are pathologically dependent on bodybuilding. Finally, all the research conducted to date by this research team has been in the United Kingdom. Cross cultural research is necessary to examine the nature and prevalence of this phenomenon in other countries and to confirm whether these British findings can be generalised to other cultures.

\section{Authors' affiliations}

D Smith, Department of Sport and Exercise Sciences, University College Chester, University of Liverpool, Chester, UK

B Hale, University of Maine, Orona, Maine, USA

\section{REFERENCES}

1 Pierce EF. Exercise dependence syndrome in runners. Sports Med 1994:18:149-55.

2 Fussell S. Muscle: confessions of an unlikely bodybuilder. London: Abacus, 1991.

3 Klein AM. Little big men. Albany: State University of New York Press, 1993.

4 Little J. Mike Mentzer: compos sui (part one). Bodybuilding Monthly 1986;9(12):31-44.

5 Thompson $\mathrm{H}$ (writer and presenter), Mares AK (producer). Iron maidens. Manchester: BBC Radio 4, 1993

6 Fisher LA. Case studies of female bodybuilders: culture gone awry? Proceedings of the Association for the Advancement of Applied Sport Psychology. Denton, TX: RonJon Publishing, 2001:8-9.

7 Little JC. Neurotic illness in fitness fanatics. Psych Ann 1979;9:49-56.

8 Sachs ML, Pargman D. Running addiction: a depth interview approach. J Sport Behav 1979;2:143-55.

9 DeBenedette V. Are your patients exercising too much? Phys Sportsmed 1990;18:119-22.

10 Carmack MA, Martens R. Measuring commitment to running: a survey of runners' attitudes and mental states. J Sport Psychol 1979; 1:25-42.

11 Chapman CL, DeCastro JM. Running addiction: measurement and associated psychological characteristics. J Sports Med Phys Fitness 1990;30:283-90.

12 Rudy EB, Estok PJ. Measurement and significance of negative addiction in runners. West J Nurs Res 1989;11:548-58.
13 Pasman L, Thompson JK. Body image and eating disturbance in obligatory runners, obligatory weightlifters and sedentary individuals. Int J Eat Disord 1988;7:759-69.

14 Ogden J, Veale D, Summers Z. The development and validation of the Exercise Dependence Questionnaire. Addict Res 1997;5:343-53.

15 Harlow RG. Masculine inadequacy and compensatory development of physique. J Pers 1951;19:312-23.

16 Darden E. Sixteen personality factor profiles of competitive bodybuilders and weightliffers. Res Q 1972;43:142-7.

17 Lantz CD, Rhea DJ, Mayhew JL. The drive for size: a psycho-behavioral model of muscle dysmorphia. International Sports Journal 2001:71-86.

18 Smith D, Hale BD, Collins DJ. Measurement of exercise dependence in bodybuilders. J Sports Med Phys Fitness 1998;38:1-9.

19 Veale D. Does exercise dependence really exist? In: Annett J, Cripps B, Steinberg $\mathrm{H}$, eds. Exercise addiction: motivation for participants in sport and exercise. Leicester: British Psychological Society, 1-5.

20 Morgan WP. Negative addiction in runners. Phys Sportsmed 1979;7:57-70.

21 American Psychiatric Association. Diagnostic and statistical manual of mental disorders. 4th ed. Washington, DC: APA, 1994.

22 Hurst R, Hale B, Smith D, et al. Exercise dependence, social physique anxiety, and social support in experienced and inexperienced bodybuilders and weightlifters. Br J Sports Med 2000;34:431-5.

23 Richman JM, Rosenfeld LB, Hardy CJ. The Social Support Survey: an initial evaluation of a clinical measure and practice model of the social support process. Res Soc Work Pract 1993;3:288-311.

24 Hart EA, Leary MR, Rejeski WJ. The measurement of social physique anxiety. Journal of Sport and Exercise Psychology 1989;11:94-104.

25 Hale BD, James B, Stambulova N. Determining the dimensions of the Athletic Identity Measurement Scale: a 'Herculean' cross-cultural effort. Int J Sport Psychol 1999;30:83-100.

26 Rhea DJ, Lantz D. Conceptualization and measurement of muscle dysmorphia. Proceedings of the Association for the Advancement of Applied Sport Psychology. Denton, TX: RonJon Publishing, 2001:8.

27 Fox KR, Corbin CB. The Physical Self-Perception Profile: development and preliminary validation. Journal of Sport and Exercise Psychology 1989:11:408-30.

28 Garner DM, Olmstead MP, Bohr Y, et al. The eating attitudes test: psychometric features and clinical correlates. Psychol Med 1982;12:871-8.

29 McNair DM, Lorr M, Droppleman LF. Profile of Mood States manual. San Diego: Educational and Industrial Testing Service, 1971.

30 Garner DM, Olmsted MP, Polivy J. Development and validation of a multidimensional Eating Disorder Inventory for anorexia nervosa and bulimia. Int J Eat Disord 1983:2:15-34.

31 Kelloway EK. Using LISREL for structural equation modeling: a researcher's guide. Thousand Oaks, CA: Sage, 1998.

32 Kline P. The handbook of psychological testing, 2nd ed. New York: Routledge, 2000.

33 Pope HG, Phillips KA, Olivardia R. The Adonis complex. New York: Free Press. 